\title{
Study on the influence of bus suspension parameters on ride comfort
}

\author{
Le Xuan Long', Le Van Quynh ${ }^{2}$, Bui Van Cuong ${ }^{3}$ \\ Faculty of Automotive and Power Machinery Engineering, Thai Nguyen University of Technology, \\ Thai Nguyen, Vietnam \\ ${ }^{2}$ Corresponding author \\ E-mail: ${ }^{1} x u a n l o n g \_0307 @ y a h o o . c o . u k,{ }^{2}$ lequynhdl@yahoo.com, ${ }^{3}$ buivancuong1301@gmail.com
}

Received 29 September 2018; accepted 7 October 2018 DOI https://doi.org/10.21595/vp.2018.20271

Check for updates

Copyright $(C) 2018$ Le Xuan Long, et al. This is an open access article distributed under the Creative Commons Attribution License, which permits unrestricted use, distribution, and reproduction in any medium, provided the original work is properly cited.

\begin{abstract}
This study proposes a three-dimensional vibration model of bus with 10 DOF (degree of freedom) based on Dragan Sekulić model to analyze the suspension parameters directly influenced ride comfort. The suspension parameters which include the stiffness and damping parameters are analyzed based on the weighted r.m.s. (root-mean-square) acceleration responses of the space of a driver, passenger in the middle part of the bus and passenger in the rear overhang according to ISO 2631-1:1997. The results show that both stiffness and damping parameters of vehicle suspension have important influences on ride comfort. Especially, the stiffness and damping values of vehicle suspension are within the value ranges $\left(0.5 k_{0} \leq k \leq 0.75 k_{0}\right)$ and $\left(0.5 c_{0} \leq c \leq 0.75 c_{0}\right)$ to improve the ride comfort of driver and passengers.
\end{abstract}

Keywords: bus seat, suspension system, full-vehicle vibration model, weighted r.m.s. acceleration, ride comfort.

\section{Introduction}

Suspension system is one of the important components to connect a vehicle body and its wheel, which not only affects the vehicle ride comfort, but also has the negative effects on the road surface as well as safe driving. Parameters matching, and optimization of suspension system are an important approach to improve vehicle ride comfort. In order to improve the ride comfort, road holding, workspace and preventing rollover, the method for the optimized design of the vehicle suspension system, considering a full vehicle model with 11-DOF based on the vertical acceleration values of seats was presented [1] and the optimal parameters of passive suspension system was found to improve ride comfort and rollover resistance including safety of the vehicle design. The MatLab/Simulink model of 7-DOF full vehicle model was developed and a genetic algorithm optimization technique was used to find the optimum values of spring stiffness and damping coefficient for front and rear passive suspension system at variable velocities which improve the vehicle ride performance [2]. The optimal parameters of passive and semi-active suspension systems using the Pareto front optimization method in respect with ride comfort and road holding were presented [3] and the active control strategy was applied to the full-bus suspension system to improve ride comfort [4]. The bus spatial vibration model with 10-DOF was developed to analyze the effects of vibrations on vehicle ride comfort and the analytical results have shown that the allowable vibration exposure time for the driver's body decreases as the spring stiffness of the driver's seat suspension system increases [5].

The evaluation method based on passenger crowdsourcing mode was proposed, which can fully perceive the vibration signals in different positions in the bus and indicate the vibration comfort in real time [6]. The domestic vehicle was chosen as the research object which 2-DOF vibration model was established according to the vehicle dynamics theory [7]. Then, the root mean square value of each vibration response was calculated by MatLab software when vehicle moves on grade $\mathrm{C}$ road surface and the study results indicate that the influence rule of each parameter of suspension on the vehicle ride comfort was obtained.

A full-vehicle vibration model with 10 DOF for 2-axle bus considering air suspension systems 
and seat suspension systems was established based on Dragan Sekulić model [5]. Vibration differential equations and MatLab, Simulink model is established to simulate for full-vehicle vibration model with the random road surface profile according to the international standard ISO 8068 [8]. The influences of vehicle suspension parameters such as stiffness and damping coefficients on seat's driver/passenger comfort is analyzed according to the international standard ISO 2631-1 (1997) [9].

\section{Bus vibration model}

A bus IK-301 with the dependent suspension systems including an air bag and two air bags for front and rear suspension systems was selected for establishing vehicle vibration model. And the vibration model with 10-DOF was established by Dragan Sekulić [5] to analyze the seat comfort of bus IK-301, as shown in Fig. 1.

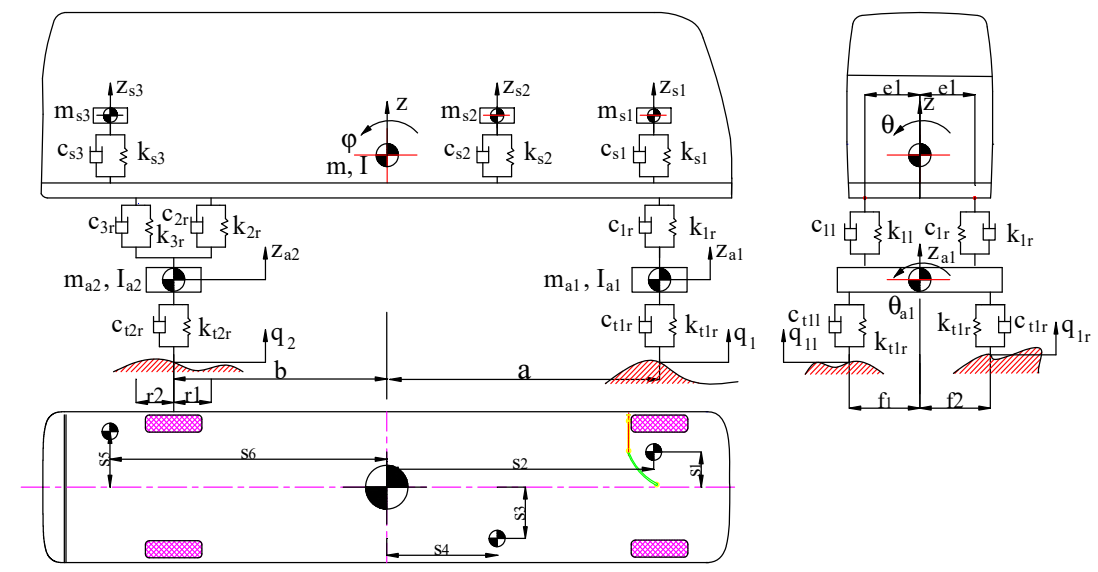

Fig. 1. 3-D dynamic model of the bus IK-301

Fig. $1, k_{i j}$ are the single air bag stiffness coefficients; $c_{i j}$ are the single shock-absorber damping coefficients; $k_{t k j}$ are the single tire stiffness coefficients; $c_{t k j}$ are the single tire damping coefficients; $m$ are the elastic-suspended mass of the fully loaded bus; $m_{a 1}$ and $m_{a 2}$ are the front and rear axle mass; $m_{s i}$ are the mass of the driver and seat, mass of the passenger 1 and seat and mass of the passenger 2 and seat; $a$ and $b$ are the distances from the front and rear axles to the bus center of gravity; $s_{n}, r_{k}, f_{k}$ and $e_{k}$ are the distances, respectively; $\varphi, \theta$ and $\theta a_{k}$ are the angular displacements at the center of gravity of the elastic-suspended mass of the fully loaded bus and axles, respectively; $I$ and $I_{a k}$ are the moments of inertia of the elastic-suspended mass of the fully loaded bus and axles, respectively; $q_{k j}$ are the random road surface profiles; $v$ is the speed of vehicle ( $i=1,2,3, k=1,2$ and $n=1 / 6$ and $j=$ left, right).

The vehicle vibration equations can be formulated in different ways. One of the most popular methods is the Lagrange equation type II. For the vibration model showed in Fig. 1, the general vibration differential equation for the bus IK-301 is represented as the standard form of matrix equation:

$m\{\ddot{z}\}+c\{\dot{z}\}+k\{z\}=\left\{F_{t}\right\}$,

where, $m, k$ and $c$ indicate the mass matrix, stiffness matrix and damping matrix of vehicle and seats, respectively; the $\ddot{z}, \dot{z}$ and $z$ respectively refer to the acceleration, velocity, displacement vectors of vehicle and seats; $F_{t}=k_{t}\{q\}+c_{t}\{\dot{q}\}$, is the vector of wheel-road contact forces, where $k_{t}$ and $c_{t}$ indicate the tire stiffness matrix and tire damping coefficient matrix of wheels, respectively, $q$ is the random road excitation vector. 


\section{Random road surface excitation}

There are two main methods for obtaining the random road surface excitation such as experimental measurement and numerical simulation using a time-domain model. In this study, the random road surface excitation is depicted by numerical simulation method [10]. Road profile is typically assumed to be homogeneous and isotropic Gaussian random process and its statistical characteristics can be described by PSD. According to the International Standards Organization (ISO) 8608 [8], PSD of road roughness can be defined as Eq. (2):

$G_{q}(n)=G_{q}\left(n_{0}\right)\left(\frac{n}{n_{0}}\right)^{-w}$

where, $n$ is spatial frequency in $\mathrm{m}^{-1}, n_{0}$ is reference spatial frequency with a value of $0.1 \mathrm{~m}^{-1}$, $G_{q}\left(n_{0}\right)$ is PSD value for reference spatial frequency in $\mathrm{m}^{3}, w$ is termed waviness, and reflects approximate frequency structure of the road profile, commonly taken as $w=2$.

Eq. (2) leads to estimation errors (overrated phenomenon) especially at low frequencies. To deal with this problem, PSD of road roughness based on rational white noise signal is proposed $[10,11]$, and Eq. (2) can be modified as follows:

$G_{q}(\omega)=\frac{\alpha \rho^{2}}{\pi\left(\alpha^{2}+n^{2}\right)}$

where, $v$ represents velocity of the vehicle in $\mathrm{m} / \mathrm{s}, \rho^{2}$ represents variance of road roughness.

Time domain representation of the road can be given as:

$\dot{q}(t)+\alpha v q(t)=w(t)$,

where, $q(t)$ is the random road excitation; $w(t)$ is the white noise sequence.

Simulink of MatLab can be used to solve the process described by Eq. (4) to generate random road profiles, the entry of the process is the standard deviation of the white noise process which depends of the road surface category, a $80 \mathrm{~km} / \mathrm{h}-22,2 \mathrm{~m} / \mathrm{s}$ speed and other parameter values [12] are set. Simulink model of random road generator is shown in Fig. 2(a) and the simulation result of the typical grade B road surface is shown in Fig. 2(b).

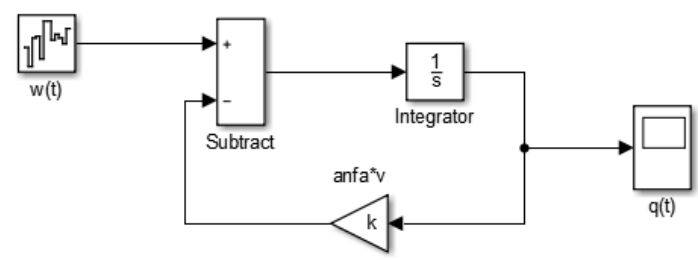

a) Simulink model of random road generator

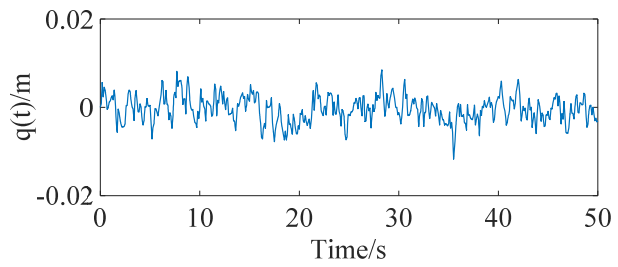

b) Grade B road profile

Fig. 2. Simulink model of random road generator and simulation result

\section{Vehicle ride comfort evaluation method}

Currently there are many methods to evaluate the vehicle ride comfort such frequency-domain method, time-domain method. This study is based on ISO 2631-1 (1997), the vibration evaluation based on the basic evaluation method including measurements of the weighted root-mean-square (r.m.s.) acceleration is defined by:

$a_{w}=\left[\frac{1}{T} \int_{0}^{T} a_{w}(t) d t\right]^{1 / 2}$, 
where, $a_{w}(t)$ is the weighted acceleration (translational and rotational) as a function of time, $\mathrm{m} / \mathrm{s}^{2}$; $T$ is the duration of the measurement, $s$.

In this way, a synthetic index-called vertical weighted rms acceleration, $a_{w z}$ can be calculated from formula Eq. (5) and the rms. value of the vertical acceleration in vehicle would be compared with the values in Table 1, for indications of likely reactions to various magnitudes of overall vibration in the public transport.

Table 1. Comfort levels related to $a_{w}$ threshold values

\begin{tabular}{|c|c|}
\hline$a_{w} /\left(\mathrm{m}_{\mathrm{s}} \mathrm{s}^{2}\right)$ & Comfort level \\
\hline$<0.315$ & Not uncomfortable \\
\hline $0.315 / 0.63$ & A little uncomfortable \\
\hline $0.5 / 1.0$ & Fairly uncomfortable \\
\hline $0.8 / 1.6$ & Uncomfortable \\
\hline $1.25 / 2.5$ & Very uncomfortable \\
\hline$>2$ & Extremely uncomfortable \\
\hline
\end{tabular}

\section{Simulation and analysis results}

In this study, MatLab software and Simulink toolbox are selected to solve Eq. (1) with the vehicle simulation parameters [5] and the random road surface excitation. The simulations are carried out when vehicle moves on the ISO good road (grade B) condition and the bus speed of $22,2 \mathrm{~m} / \mathrm{s}$ with full load. The vertical acceleration responses of the space of a driver, passenger in the middle part of the bus and passenger in the rear overhang is shown in Fig. 3.

The value of $a_{w s 1}$ is defined as $0.199 \mathrm{~m} \cdot \mathrm{s}^{-2}$ and this value of $a_{w s 1}$ satisfies the conditions for driver comfort (according to Table 1); the values of $a_{w s 2}$ and $a_{w s 3}$ are defined as $0.621 \mathrm{~m} . \mathrm{s}^{-2}$, $0.685 \mathrm{~m} . \mathrm{s}^{-2}$, respectively and this values satisfy uncomfortable conditions for passengers (according to Table 1). Both stiffness and damping parameters of vehicle suspension have important influences on vehicle ride comfort. In order to analyze the influence of bus suspension parameters such as stiffness and damping coefficients on ride comfort, discussions will present in the following section.

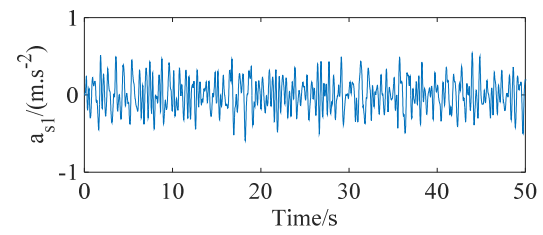

a) The space of a driver

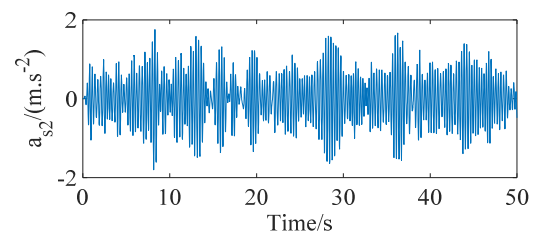

b) Passenger in the middle part

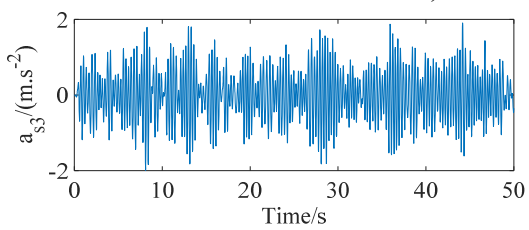

c) Passenger in the rear overhang

Fig. 3. The vertical acceleration responses of bus seats

\subsection{Influence of vehicle suspension stiffness}

Vehicle suspension stiffness is an important factor that influences the ride comfort. To analyze its effect on the $a_{w s 1}, a_{w s 2}$ and $a_{w s 3}$ values, the values of suspension stiffness coefficients

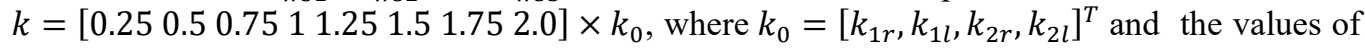
suspension damping coefficients $c=\left[\begin{array}{l}0.250 .50 .7511 .251 .51 .752 .0\end{array}\right] \times c_{0}$, where $c_{0}=$ $\left[c_{1 r}, c_{1 l}, c_{2 r}, c_{2 l}\right]^{T}$ were analyzed when vehicle moves on the ISO good road (grade B) condition 
and the bus speed of $22,2 \mathrm{~m} / \mathrm{s}$ with full load, where $k_{0}$ and $c_{0}$ are used to designate the vehicle stiffness and damping coefficients in the reference document [5]. The influence of vehicle suspension stiffness coefficients on $a_{w s 1}, a_{w s 2}$ and $a_{w s 3}$ values are shown in Fig. 4.

From Fig. 4 shows that when the vehicle suspension stiffness coefficient increases, the $a_{w s 1}$, $a_{w s 2}$ and $a_{w s 3}$ values tend to increase, which makes the negative effects on ride comfort of driver and passengers. The $a_{w s 1}$ values increase quickly when the values of the damping coefficients are $c=0.25 c_{0}$ and the $a_{w s 1}, a_{w s 2}$ and $a_{w s 3}$ values do not change much when the values of the damping coefficients are achieved by great values. When the values of the damping coefficients increase from $1.5 c_{0}$ to $2 c_{0}$, the $a_{w s 1}, a_{w s 2}$ and $a_{w s 3}$ values decrease about from 3.6 to $3.76 \%$, which makes the ride comfort of driver and passengers negligible.

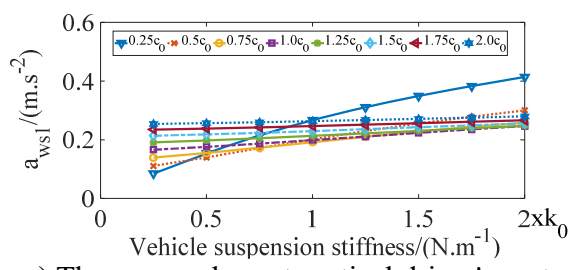

a) The $a_{w s 1}$ values at vertical driver's seat

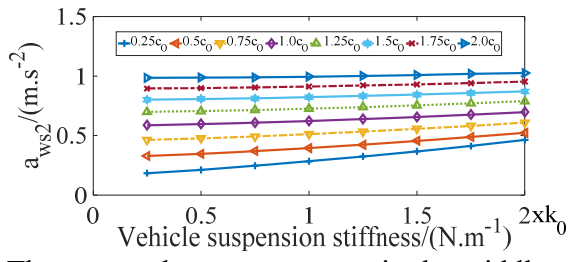

b) The $a_{w s 2}$ values at passenger in the middle part

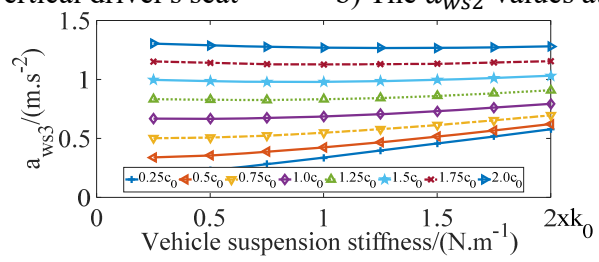

c) The $a_{w s 3}$ values at passenger in the rear overhang

Fig. 4. Influence of vehicle suspension stiffness coefficients on ride comfort of bus seats

\subsection{Influence of vehicle suspension damping}

Vehicle suspension damping is another important factor that influences the ride comfort. To analyze its effect on the $a_{w s 1}, a_{w s 2}$ and $a_{w s 3}$ values, the values of suspension damping

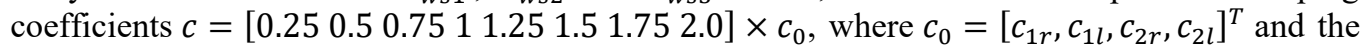

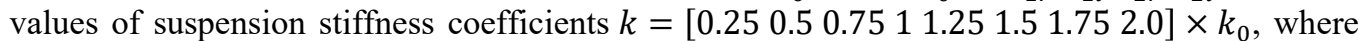
$k_{0}=\left[k_{1 r}, k_{1 l}, k_{2 r}, k_{2 l}\right]^{T}$ were analyzed when vehicle moves on the ISO good road (grade B) condition and the bus speed of $22,2 \mathrm{~m} / \mathrm{s}$ with full load. The influence of vehicle suspension damping coefficient on $a_{w s 1}, a_{w s 2}$ and $a_{w s 3}$ values are shown in Fig. 5.

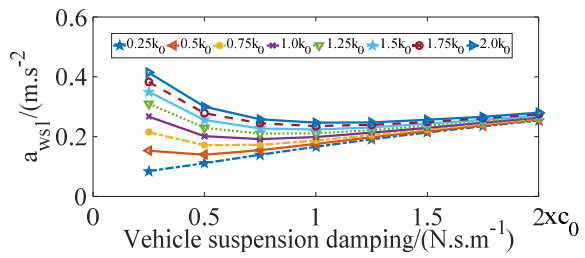

a) The $a_{w s 1}$ values at vertical driver's seat

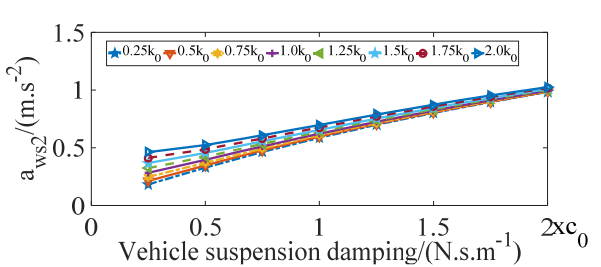

b) The $a_{w s 2}$ values at passenger in the middle

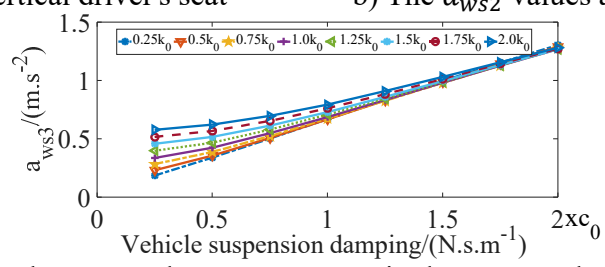

c) The $a_{w s 3}$ values at passenger in the rear overhang

Fig. 5. Influence of vehicle suspension damping coefficient on ride comfort of bus seats 
Fig. 5 shows that vehicle suspension damping coefficient increases from 0.25 to $0.75 c_{0}$, the $a_{w s 1}$ values tends to decrease, which makes driver's ride comfort considerably improve. And then the $a_{w s 2}$ and $a_{w s 3}$ values tends to increase quickly, which has the negative effects on ride comfort of passengers.

According to Fig. 4 and Fig. 5, in order to decrease the vehicle vibrations and hence improve the ride comfort, the values of the vehicle suspension parameters are within the value ranges $\left(0.5 k_{0} \leq k \leq 0.75 k_{0}\right)$ and $\left(0.5 c_{0} \leq c \leq 0.75 c_{0}\right)$.

\section{Conclusions}

This study presents a methodology to analyze the effects of bus suspension parameters on ride comfort based on the full-vehicle vibration model using the random road surface profile and the analysis results as follow:

1) In the suspension system, the reasonable matching of suspension stiffness and damping can efficiently improve seat ride comfort, which keeping ride comfort keeping ride comfort within a safety limits and the safety of the road surface.

2 ) In order to decrease the vehicle vibrations and hence improve the ride comfort, the values of the vehicle suspension parameters are within the value ranges $\left(0.5 k_{0} \leq k \leq 0.75 k_{0}\right)$ and $\left(0.5 c_{0} \leq c \leq 0.75 c_{0}\right)$.

\section{References}

[1] Seifi Abolfazl, Hassannejad Reza, Hamed Mohammad A. Optimum design for passive suspension system of a vehicle to prevent rollover and improve ride comfort under random road excitations. Proceedings of the Institution of Mechanical Engineers, Part K: Journal of Multi-body Dynamics, Vol. 230, Issue 4, 2015, p. 426-441.

[2] Geweda A. E., El Gohary M.-A., EI Nabawy A.-M., Awad T. Improvement of vehicle ride comfort using genetic algorithm optimization and PI controller. Alexandria University Alexandria Engineering Journal, 2017, Vol.56, p. 405-414.

[3] Koulocheris Dimitrios, Papaioannou Georgios, Chrysos Emmanouil A comparison of optimal semi-active suspension systems regarding vehicle ride comfort. IOP Conference Series: Materials Science and Engineering Vol. 252, 2017, p. 012022.

[4] Mujde Turkkan, Nurkan Yagiz Fuzzy logic control for active bus suspension system. Journal of Physics: Conference Series, Vol. 410, 2013, p. 0012006.

[5] Sekulic Dragan, Dedovic Vlastimir, Rusov Srdjan, Šalinic Slaviša, Obradovic Aleksandar Analysis of vibration effects on the comfort of intercity bus users by oscillatory model with ten degrees of freedom. Applied Mathematical Modelling, Vol. 37, 2013, p. 8629-8644.

[6] Zhao Hong, Guo Li Lu, Zeng Xiang Yan Evaluation of bus vibration comfort based on passenger crowdsourcing mode. Mathematical Problems in Engineering, Vol. 2016, 2016, p. 2132454.

[7] Zhang G. X., Dong Y. E. Study on the influence of suspension parameters on the vehicle ride comfort, Journal of Shaanxi University of Science and Technology (Natural Science Edition), Vol. 5, 2016, p. $147-151$.

[8] ISO 8068. Mechanical Vibration-Road Surface Profiles-Reporting of Measured Data. International Organization for Standardization, 1995.

[9] ISO 2631-1. Mechanical Vibration and Shock-Evaluation of Human Exposure to Whole-Body Vibration, Part I: General Requirements. The International Organization for Standardization, 1997.

[10] Wang Zhen Feng, Dong Ming Ming, et al. Influence of road excitation and steering wheel input on vehicle system dynamic responses. Applied Sciences, Vol. 7, Issue 6, 2017, p. 570-579.

[11] Dodds C. J., Robson J. D. The description of road surface roughness. Journal of Sound and Vibration, Vol. 31, Issue 2, 1973, p. 175-183.

[12] Quynh Le Van Vibration Study and Control Cab of Vibratory Roller. Southeast University, Nanjing, China, 2013. 